\title{
Positive education significance analysis of educational psychology on armed police officers and soldiers
}

\author{
Gaojie \\ (Armed Police Engineering University, Shaanxi xi 'an 710038)
}

\begin{abstract}
Educational psychology can help teachers understand students' psychological phenomenon and change rules in the process of taking in knowledge, skills training and psychological counseling, and grasp the relationship between education and psychological development. Armed police trainers need to master the psychological change of armed police cadets in the process of positive education, avoid their momentum loss and resistance mood, meanwhile, guide the armed police officers and soldiers develop independent personality and set up strong collective concept in special force environment. This article adopts symptom self-assessment scale (SCL - 90) to measure 325 soldiers' self evaluation of one armed police detachment. Through the analysis of the comparative study of armed police officers' positive education impact on soldiers by using educational psychology. Research results show that the application of educational psychology can help instructors understand students' psychological changes, enable them to better assist armed police students in building self concept and maintaining mental health, assist the armed police cadets constantly performing self correction and selfimprovement, so that the students can better adapt to the requirement of military professional mental health.
\end{abstract}

Keywords-Positive education; Education psychology; Armed police officers and soldiers

\section{INTRODUCTION}

Modern society's definition of health has been greatly changed. Health not only means body health, but includes a sound psychological quality and social adaptability. Only with better physical and mental health may one play his personal capacity to create more value and wealth for the society. Armed police is a special profession. Their work environment is closely related to social life. The work content of armed police officers and soldiers in recent years is more and more complex. They are not only responsible for domestic security maintenance tasks, but also are involved in fighting and emergency operations, such as daunting tasks like flood and risks, ice and disaster, forest fire, spring travel security, bullies, large activities safe. Complex task content and tough working environment require armed police officers and soldiers have higher psychological quality, which also leads to some of the armed police officers and soldiers' psychological pressure, especially the young officers and soldiers with relatively weak adaptability and identification ability. They are easy to have psychological conflict and imbalance. Psychological test results of 325 soldiers in a certain armed police detachment are shown in Table I.
TABLE I. A ARMED POLICE DETACHMENT SOLDIERS, PSYCHOLOGICAL TEST RESULTS

\begin{tabular}{|l|c|c|}
\hline \multicolumn{1}{|c|}{ indicator } & score & standard value \\
\hline Intelligence & 6.31 & $0 \sim 10$ \\
\hline Independence & 6.43 & $0 \sim 10$ \\
\hline Self-discipline & 6.44 & $0 \sim 10$ \\
\hline Stability & 7.51 & $0 \sim 10$ \\
\hline Courageousness & 8.78 & $0 \sim 10$ \\
\hline Group-liking & 8.89 & $0 \sim 10$ \\
\hline Excitatory & 9.02 & $0 \sim 10$ \\
\hline
\end{tabular}

It can be seen by the results of the survey that armed police officers and soldiers questioned has not obvious personality and independence performance because being away from family, away from home, and big work pressure. They have weak self-protection ability of mental health. Thus armed police force shall focus on strengthening students' psychological quality training and evaluation of mental health of young officers and soldiers in the process of education, promote the development impetus of armed police officers and soldiers, guide the armed police cadets develop independent personality, set up strong collective concept in the special army environment in order to modernize armed police force in the process of improving officers and soldiers psychological adaptability and endurance.

\section{THE PRESENT SITUATION AND EXISTING PROBLEMS OF CHINESE ARMED POLICE FORCE POSITIVE EDUCATION}

\section{A. The present situation of armed police force positive} education in our country

The armed police forces education in our country is mainly positive education. By active advanced education activity, rely on scientific theory force, fully mobilize positive factors and armed police cadets body role, emphasize to play armed police officers and soldiers subjective initiative, and achieve the purpose of self learning and self-improvement. Positive education for armed police force in our country mobilizes and exerts the armed police officers and soldiers' subjective initiative, arouses the mass students' inner motive power of pursuit of improving and progress. It is active study and training of students to improve the individual psychological quality and compressive ability. Liu JunLi Liu YunBo's mental health 
test results of 12486 soldiers show that positive education improved the mental health level of the trained armed police officers and soldiers. In the process of performing tasks, positive education trained officers and men will be better able to adhere to the correctness and accuracy of the action, can deal with challenges of more complicated work environment, and possess high collectivism concept. Guo Jun's study on the armed police cadets' attitude and selfcontrol study shows that the armed police forces with hard training can raise their awareness of hardships bearing. Troops' positive education can deepen the armed police officers and soldiers' understanding degree of arrangement all-obedience, improve the armed police officers and soldiers' emergency ability in coping with emotional changes in the process of difficult performing, and constantly improve the armed police officers and soldiers' self-control and self-discipline ability.

\section{B. Problems existing in armed police force's positive education in our country}

China's armed police forces' positive education mainly aims to improving the armed police officers and soldiers' obedience attitude. Obedience attitude refers to the group members' internal psychological tendency and behavior tendency when acting according to the requirements of group norms or orders from the authority leadership. Obedience attitude, absolutely necessary quality of troops, is influenced by many factors and reflects individual differences. The current main problems of armed police forces' positive education are of the following several aspects:

First of all, some instructors understand the principle of positive education, and equal positive education to true education, constantly instill germ-free teaching content into the armed police officers and soldiers, reject the fact that fake, wrong and evil incidents exist in reality, negatively avoid enemies in the society, and negatively treat enemies' influence on the development of mental health status of armed police officers and soldiers. This leads to students' strong resistance, moral confusion, and loss of self protection, etc. Some drillmasters one-sidedly emphasize on the role as the guardians of the people of armed police officers and soldiers, which makes the armed police officers and soldiers disregard their own safety to rescue and relief and causes heavy losses in the armed police force in the process of performing tasks. One-sided emphasis on positive education or positive education function scope increase will most likely reduce the actual effect of armed police force positive education.

Second, some instructors cannot very good master students psychological change process, one-sidedly understand positive education purpose, which reduces the ability of armed police officers and soldiers to distinguish true and false, resist the enemies, and pursue the true. Falses are in real life as well as the truth, along with economic development and increasingly complex social environment, in addition to shoulder the burden of maintaining the social peace, armed police officers and soldiers also bear a lot of travel on duty and security tasks such as large-scale activities. So instructors should guide armed police officers and soldiers to discern between false and true, and actively guide students to face up to the existence of the enemies, pay attention to students' psychological change in the process of accepting the enemies, and avoid students resistance mood.

Finally, the teaching task of armed police force in the new period has been changed. Armed police officers and soldiers' psychological change during the process of learning and training in the army has more obvious influence on the quality of teaching. Troops education is no longer simply focused on physical training and thought education, and contains knowledge and skills training combining a large number of theory and practice. Students need higher wisdom and understanding to convert the content into practice. Instructors need to apply heuristic teaching methods to guide students recognize questions and consider problems, instructors need to be more flexible to master students' ideological change to be able to stimulate the enthusiasm of students, and promote creativity to solve emergency response tasks in practice.

China's armed police force training pays more and more attention to actual effect. Instructors should actively learn applied educational psychology to grasp student's psychological change and the law to make broad armed police officers and soldiers gain more knowledge and skills in the process of positive education in the army.

\section{EDUCATIONAL PSYCHOLOGY'S POSITIVE EFFECT RESEARCH ON ARMED POLICE FORCE}

\section{A. Mathematics source}

Exampled by325 armed police officers and soldiers of a certain armed police detachment as the research object. The study objects are men. Tracking method is adopted to collect the self evaluation data of mental health status, obedience attitude and pressure bearing ability of the research object before and after the study, which is used to study the impact of educational psychology on positive education function for armed police officers and soldiers.

\section{B. Research variables}

The study's research objects' mental health status y1, pressure bearing ability y2, and obedience attitude y3 are the research variables. Study the objects' self-evaluation by symptom self-evaluation scale measuring, and study the role of educational psychology in positive education.

\section{Research model}

Linear regression model is applied to analyze the influence of educational psychology on positive education for armed police officers and soldiers. The model's specific formula is as follows: 
$\mathrm{y}_{i}=\beta_{0}+\beta_{1} x_{1 i}+\beta_{2} x_{2 i}+\cdots+\beta_{i} x_{i i}+u_{i}$

$i=1,2, \ldots, N \quad$ (Formula3.1)

In formula (3.1): $\mathrm{N}$ is sample number, $\mathrm{y}$ is the dependent variable, $\mathrm{x}$ is the independent variable; $\beta$ is the independent variable coefficient, $\mu$ is random perturbation term. The model uses F statistic method to test significance, and the specific calculation formula is as follows:

$$
F=\frac{\sum_{i=1}^{N}\left(y_{i}-y_{i}\right)^{2} / k}{\sum_{i=1}^{N}\left(\hat{y}_{i}-\bar{y}_{i}\right)^{2} /(N-K-1)}
$$

(Formula 3.2)

If the number of residual square sum of the model is RSS, then RSS computational formula is as follows:

$$
R S S=\sum_{i=1}^{N} \hat{\mu_{i}^{2}}=(Y-X \beta)^{\prime}(Y-X \beta)
$$

In formula (3.3), $\mu$ is random perturbation term. Ordinary least squares estimation regression coefficient is used to determine the normal equations and estimate the regression coefficient vector is as follows:

$$
b=\left(X^{\prime} X\right)^{-1} X^{\prime} Y \text { (Formula 3.4) }
$$

Random disturbance variance calculation formula is as follows:

$$
\hat{\sigma^{2}}=\frac{\sum \hat{\mu}_{i}^{2}}{N-k-1} \text { (Formula 3.5) }
$$

\section{EDUCATION PSYCHOLOGY'S INFLUENCE ON POSITIVE EDUCATION RESEARCH}

\section{A. Descriptive analysis}

As can be seen from Figure 1, the mental health status, pressure bearing ability and obedience attitude of armed police officers and soldiers varied. The difference of mental health status is the most significant, indicating that some armed police officers and soldiers are of poor mental health status, the effects of work stress, anxiety and depressive mood on armed police officers and soldiers health need attention. In addition, the result of soldiers and officers pressure-bearing capacity is stronger than that of Xie Jun's (2005) study. And obedience attitude result is close to that of the object in this study, which indicates relatively ideal consciousness obedience of the armed police detachment, and they have strong team consciousness and strong obedience consciousness.

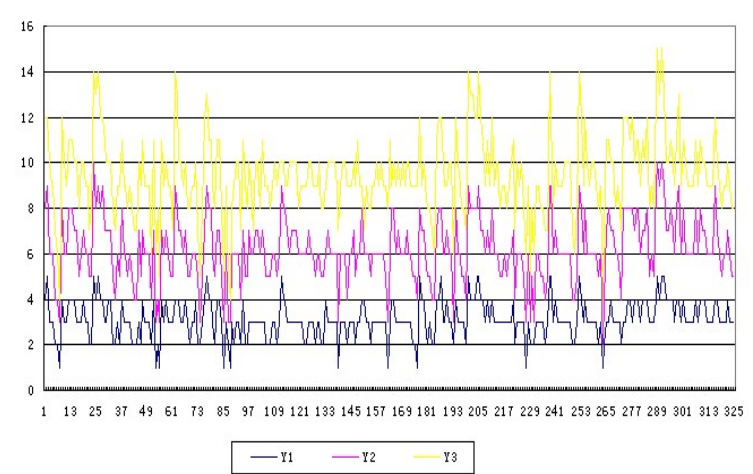

Figure 1. Dependent variable regression results

\section{B. Empirical result analysis}

TABLE II. ARMED POLICE OFFICERS AND SOLDIERS' SELF EVALUATION COMPARISON RESULTS

\begin{tabular}{|l|c|c|c|}
\hline \multicolumn{1}{|c|}{ Project } & T=1 & T=2 & Each factor comparison \\
\hline Intelligent factor & 2.49 & 2.51 & $\mathrm{~T} 1<\mathrm{T} 2$ \\
\hline Independent factor & 2.98 & 3.67 & $\mathrm{~T} 1<\mathrm{T} 2$ \\
\hline Self-discipline factor & 2.52 & 2.53 & $\mathrm{~T} 1<\mathrm{T} 2$ \\
\hline Stability factor & 4.12 & 4.56 & $\mathrm{~T} 1<\mathrm{T} 2$ \\
\hline Courageousness factor & 4.44 & 4.42 & $\mathrm{~T} 1>\mathrm{T} 2$ \\
\hline Group-liking factor & 4.35 & 4.36 & $\mathrm{~T} 1<\mathrm{T} 2$ \\
\hline Exciting factor & 3.77 & 3.52 & $\mathrm{~T} 1>\mathrm{T} 2$ \\
\hline
\end{tabular}

In Table II, $\mathrm{T}=1$ is the officers and soldiers selfassessment results before taking educational psychology intervention teaching. $\mathrm{T}=2$ is the officers and soldiers selfassessment results after taking educational psychology intervention teaching. It can be seen from the results that the instructor teaching mode change affected the psychological state and learning effect of trained officers and men. Their independence and stability are more obvious, which indicates that while trainers are paying attention to students' psychological change, the formation of the independent students' personality is more obviously guided. They have more psychological stability in the face of sudden tasks, and not obviously affected by working environment and tasks performed in that students can be more resilient after training. Exciting factor is greatly reduced; in addition, which shows that after training, students can reduce psychological change through self learning and self adjusting, and relieve work pressure's impact on health through self correction and selfimprovement. Finally, students' intelligence, self-discipline, courageousness and group-liking did not change significantly in the two surveys, which indicates that in the process of instructors adopting education psychology to intervene participants psychological change, there is little impact on the students knowledge learning and self-control, self-discipline. The instructor needs to improve teaching 
methods to enhance psychological intervention's influence on the students' knowledge acceptance and skill ability.

From the results of application, it can be seen that armed police instructor applies educational psychology to intervene the process of students' psychological change, which can improve the effects of positive education for police force. So this article puts forward the following Suggestions: first, through various channels enrich armed police instructors teaching methods. In view of the special training environment for the police force, instructors are promoted to learn more about students psychological change rules, and effectively intervene students' psychological changes to strengthen the positive education forces. Second, pay attention to the mental health status of the armed police officers and soldiers. Good mental health can reduce the tendency of rejecting in accepting the positive education, and can reduce the pressure from work, life and family influence on students. Armed police officers and soldiers can concentrate on efficient completion of the task, decrease human error in the process of completing the task because of psychological instability, and maximally save the armed police forces' fighting capacity. Finally, although China has a lot of research achievements studying of troops, but few researches is from the perspective of instructors and studies armed police officers and soldiers' psychological change in the process of positive education. Combining psychology with the traditional education can promote the positive effect of education in our country, so we need more research on armed police education ways and methods to promote armed police force in China.

\section{CONCLUSION}

This paper tracks armed police students' self-evaluation, applies regression analysis method to study education psychology effects in the process of positive education on students. Research results show that the armed police instructor should focus on the psychological change and its law of armed police officers and soldiers to avoid students' momentum loss and resistance, and guide the armed police cadets develop independent personality in a special military school environment and set up strong collective concept in knowledge acceptance, skills training and psychological counseling process.

\section{REFERENCES}

[1] G. Eason, B. Noble, and I. N. Sneddon, "On certain integrals of Lipschitz-Hankel type involving products of Bessel functions,” Phil. Trans. Roy. Soc. London, vol. A247, pp. 529-551, April 1955. (references)

[2] J. Clerk Maxwell, A Treatise on Electricity and Magnetism, 3rd ed., vol. 2. Oxford: Clarendon, 1892, pp.68-73.

[3] I. S. Jacobs and C. P. Bean, "Fine particles, thin films and exchange anisotropy,” in Magnetism, vol. III, G. T. Rado and H. Suhl, Eds. New York: Academic, 1963, pp. 271-350.

[4] K. Elissa, “Title of paper if known,” unpublished.

[5] minutes

[6] R. Nicole, “Title of paper with only first word capitalized,” J. Name Stand. Abbrev., in press.

[7] Y. Yorozu, M. Hirano, K. Oka, and Y. Tagawa, "Electron spectroscopy studies on magneto-optical media and plastic substrate interface,” ASME Transl. J. Magn. Japan, vol. 2, pp. 740-741, August 1987 [Digests 9th Annual Conf. Magnetics Japan, p. 301, 1982].

[8] M. Young, The Technical Writer's Handbook. Mill Valley, CA: University Science, 1989.

[9] Electronic Publication: Digital Object Identifiers (DOIs):

Article in a journal:

[10] D. Kornack and P. Rakic, "Cell Proliferation without Neurogenesis in Adult Primate Neocortex,” Science, vol. 294, Dec. 2001, pp. 2127 2130, doi:10.1126/science.1065467.

Article in a conference proceedings:

[11] H. Goto, Y. Hasegawa, and M. Tanaka, "Efficient Scheduling Focusing on the Duality of MPL Representatives," Proc. ASME Symp. Computational Intelligence in Scheduling (SCIS 07), ASME Press, Dec. 2007, pp. 57-64, doi:10.1109/SCIS.2007.357670. 